\title{
$N 87-11086$
}

A FLOODED-STARVED DESIGN FOR NICKEL-CADMIUM CELLS

\author{
Lawrence H. Thaller \\ National Aeronautics and Space Administration \\ Lewis Research Center \\ Cleveland, $\mathrm{OH} 44135$
}

\section{INTRODUCTION}

Sealed nickel-cadmium cells for aerospace applications have been made for several decades by a variety of manufacturers. Although each manufacturer has his own set of processes, procedures, and design techniques, these cells owe much of their long cycle life to the electrochemical couples employed and the physical properties of the separator material used. This material has the combination of pore size distribution and wetting characteristics which permits the oxygen evolved at the positive electrode during the latter stages of charge to have access to the metallic cadmium on the negative electrode while at the same time holds enough electrolyte to maintain good ionic conductivity between the electrode pairs. This condition is usually referred to as being "starved" in terms of the amount of electrolyte. Depending on the particular separator type and number of layers, the characteristics of the electrodes, and the compression on the plate pack, an electrolyte loading value $\left(X \mathrm{~cm}^{3} / \mathrm{Ahr}\right)$ will yield the proper balance in terms of gas permeability and electrolyte conductivity. A particular manufacturer will aim for a certain cell pressure on overcharge based on the experience gained from past performance.

There are several possible difficulties associated with this general procedure which may well result is substandard performance of the cell. This results in part from the statistical aspects among groupings of plate packs and/or cell sets and in part from the growth with cycling characteristics of the electrodes used in these cells.

It is the purpose of this paper to describe in detail a somewhat analogous situation among groupings of alkal ine fuel cells where the stochastic aspects have been much more accurately documented and then illustrate how this problem was eliminated using straight forward principles of pore size engineering (Ref. 1). This is followed by a suggested method of adapting these same design principles to nickel-cadmium cells. It must be kept in mind that when cells are cycled to typically twenty percent depth of discharge that eighty percent of the weight of the cell is simply dead weight. Some of this dead weight might be put to better use by trading it for a scheme that would increase the time during which the cell would be working more closely to its optimum set of operating parameters.

\section{BACKGROUND}

In the early stages of the development of alkaline fuel cell technology at 
what is now called International Fuel Cells, a cell was made up as shown in figure 1. These cells employed a fixed, trapped amount of electrolyte within each cell. The oxygen electrode was a thin screen onto which was placed a mixture of catalyst powder and Teflon. The Teflon content was such as to render the electrode wet proof. The separator was an asbestos mat fully filled with electrolyte and the hydrogen electrode was a thick ( 0.060 in.) sheet of sintered nickel which was catalyzed more or less uniformly

throughout. The pore sizes of the individual components were selected so that the separator would at all times be filled with electrolyte. The

electrolyte-gas interface would be set up somewhere within the thick nickel sinter. As conditions arose that resulted in temporary changes in the volume of the electrolyte, this interface simply moved slightly to the right or left.

OPTIMUM VOLUME

Optimum volume is a term that is used to describe the effect of electrolyte volume on cell performance and in particular that volume which results in the peak performance of the cell. The reason for a change in performance with cell electrolyte volume (interface position) and an optimum volume can be readily seen with the help of this diagram. If the electrolyte-gas interface is very close to the gas cavity (right hand edge of the hydrogen electrode) then most of the catalytic surface is covered over with electrolyte. The slow diffusion of hydrogen through the bulk electrolyte along with the relatively high ionic IR drop across this thick electrode will result is poor cell performance. As the interface recedes into the sintered electrode, there will be a greater degree of electrolyte film-catalyst surface-gas interface, and performance will increase. As this interface apporaches the matrix, the diffusion of gas into and water vapor out of this sinter becomes the controlling factor and again performance falls off. This discussion is not meant to imply any similarity between a nickel-cadmium cell and a hydrogen-oxygen fuel cell. It is only meant to illustrate how a cell can have a preferred amount of electrolyte for optimum operation. An interesting series of experiments were carried out on a group of 36 individual cells of this type which illustrates several characteristics of groupings. Using a technique which is peculiar to the fuel cell industry and is not particularly germane to the discussion at hand, the optimum volumes of each one of these cells was determined. Figure 2 shows the histogram of these results. The results, of course, show a considerable standard deviation or spread in the values of the optimum volume. These results are particularly significant in that fuel cells are filled as a group that are stacked together in a manner that results in each cell receiving approximately the same volume. This, of course, would result in some cells receiving more than their optimum amount and some cells receiving less than their optimum amount. Before being able to discern whether this would result in acceptable or unacceptable performance of this particular grouping of cells, a second characteristic called volume tolerance, must be known. As the name implies, volume tolerance describes the cell performance as a function of the electrolyte volume. In essence, the shape of the electrolyte volume vs. cell 
performance curve is a measure of the volume tolerance of the cell. Without going into the details of the matter, it can be stated (and it should be obvious) that if the grouping of celis as shown in figure 2 were all filled with $13 \mathrm{~cm}^{3}$ of electrolyte, then three of the cells would be over filled where as eight cells would be under filled.

The answer to this problem in the fuel cell industry was the invention of what was called the electrolyte reservoir (Ref. 2). The thick nickel sinter electrode (figure 3 ) was replaced with a thin screen-Teflon-catalyst type gas electrode similar to the oxygen electrode. Placed behind the hydrogen electrode was a porous nickel sinter with a waffled pattern on it so that reactant gas could flow on the back side of the electrode while the sinter would also be in contact with it. Here again, the pore size and pore size distribution of each component is carefully selected so as to maintain proper electrolyte placement. The electrolyte reservoir has the largest pore size of wettable material so that is will freely accept and give up electrolyte as the cell undergoes temporary wetting or drying conditions. The electrodes themselves under normal conditions do not undergo any changes in their electrolyte volume; only changes in the electrolyte concentration as the water content temporarily is in excess of or is less than that value about which the control point is fixed. Figure 4 is a plot of the volume tolerance characteristics of three different cell constructions that have been used over the years by IFC. The slanted straight line depicts the characteristics of the cells that employ the electrolyte reservoir behind the screen hydrogen electrode. The curve showing the intermediate degree of volume tolerance was the configuration described earlier with the thick sintered electrode. The cell construction showing a very minimal amount of volume tolerance was of yet an earlier level of technology. Cells with the widest degree of volume tolerance are the type used aboard the space shuttle. Groupings of these cells are much less affected by the stochastic aspects associated with groupings of individual cells.

\section{FLOODED STARVED DESIGN FOR NICKEL-CADMIUM CELLS}

It would not be incorrect to say that a nickel-cadmium cell has an optimum electrolyte volume associated with it. The optimum electrolyte volume in this case is related to the balance required between the cell ionic resistance and the gas recombination characteristics. Further, it probably would not be incorrect to say that among a grouping of cells there would be a certain distribution associated with the optimum volume values. It is however conjectural at this point to state that when a group of cells are filled, some are overly filled while others are under filled. Likewise, it would probably be dangerous to state that the growth characteristics of the nickel electrode, coupled with the chemical degradation of the nylon separator material in the $\mathrm{KOH}$ and oxidative environment, would result in adverse effects on the cell optimum volume, but it certainly can't do it any good. What is suggested is to adopt, where feasible, some of the techniques used in the alkaline fuel cell field into the nickel-cadmium technology. Figure 5 shows a simplistic diagram of a nickel-cadmium cell that employs an electrolyte reservoir 
consisting of a wettable material with a pore size intermediate between the large gas filled pores and the small electrolyte filled pores of the separator. Even in well behaved nickel electrodes, there is an increase in the fine pore structure of the active material which would tend to draw electrolyte out of the separator (Ref. 1). If a reservoir were present it could yield up electrolyte as needed to replace the amount lost to the electrodes. The placement of the reservoir at the bottom is just meant to be illustrative. Depending on the pore size characteristics of the separator, the reservoir function could be performed by the separator itself. It should be noted here that there are driving forces other than capillary pressure (pore size) that come into play in these cells and need to be taken into account when doing an overall cell design. They include diffusional forces and migrational forces and possibly some electro-osmotic effects. In nickel-cadmium cells in contrast to nickel-hydrogen cells, there is a greater amount of electrolyte volume change due to the water associated with the electrochemical reaction. follows:

The steps involved in designing a flooded-starved cell might proceed as

1) Investigate the electrolyte volume tolerance characteristics of nickel-cadmium cells. This should be done both from an optimum volume point of view as well as a volume tolerance point of view.

2) Investigate the stochastic aspects of the optimum volume characteristics so the degree of variance within a cell population can be estimated.

3) Establish the net plate expansion characteristics (while under the pack compression) of both the nickel and cadmium electrodes.

4) Establish the pore size and pore size distribution characteristics of the cell plates as a function of cycling, electrolyte composition, plate additive, etc.

5) Establish the pertinent physical characteristics of chemically stable oxidation resistant separator materials. These would include their compressibility-pore size distribution characteristics.

6) Calculate the reservoir requirements so as to keep the $\operatorname{cell}(\mathrm{s})$ within proper electrolyte tolerance bounds over the expected lifetime of the cell $(\mathrm{s})$.

SUMMARY

A methodology for increasing or extending useful lives of nickel-cadmium cells and batteries is suggested based on a somewhat analogous situation that was present in early technology trapped electrolyte alkaline fuel cells. The 
fuel cell industry was able to document and quantize the problem. The solution came when the volume tolerance characteristics of the cells were widened. This same approach is suggested for first quantifying the problem and then gathering the required data to develop a modified nickel-cadmium cell design.

\section{REFERENCES}

1. Abbey, K. M. and Thaller, L. H.: Proc. 17th IECEC, Vol. 2, pp 757-764, 1982.

2. U. S. Patent No. 3,779,811 (1973); "Matrix-Type Fuel Ce11;" Stedman, J. K. and Bushnel1, C. L. 


\section{ORIGINAL PAGE IS}

OF POOR QUALITY

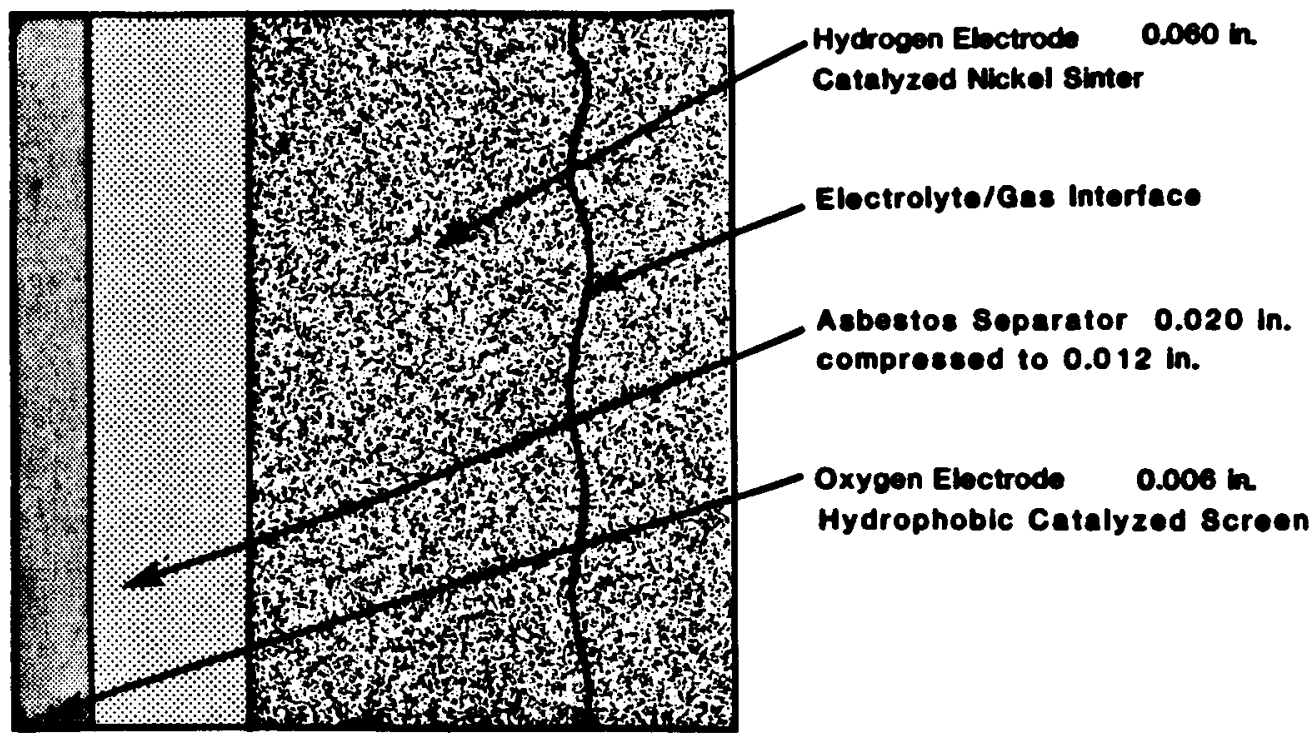

Figure 1. SCHEMATIC OF A SINTER-SCREEN FUEL CELL

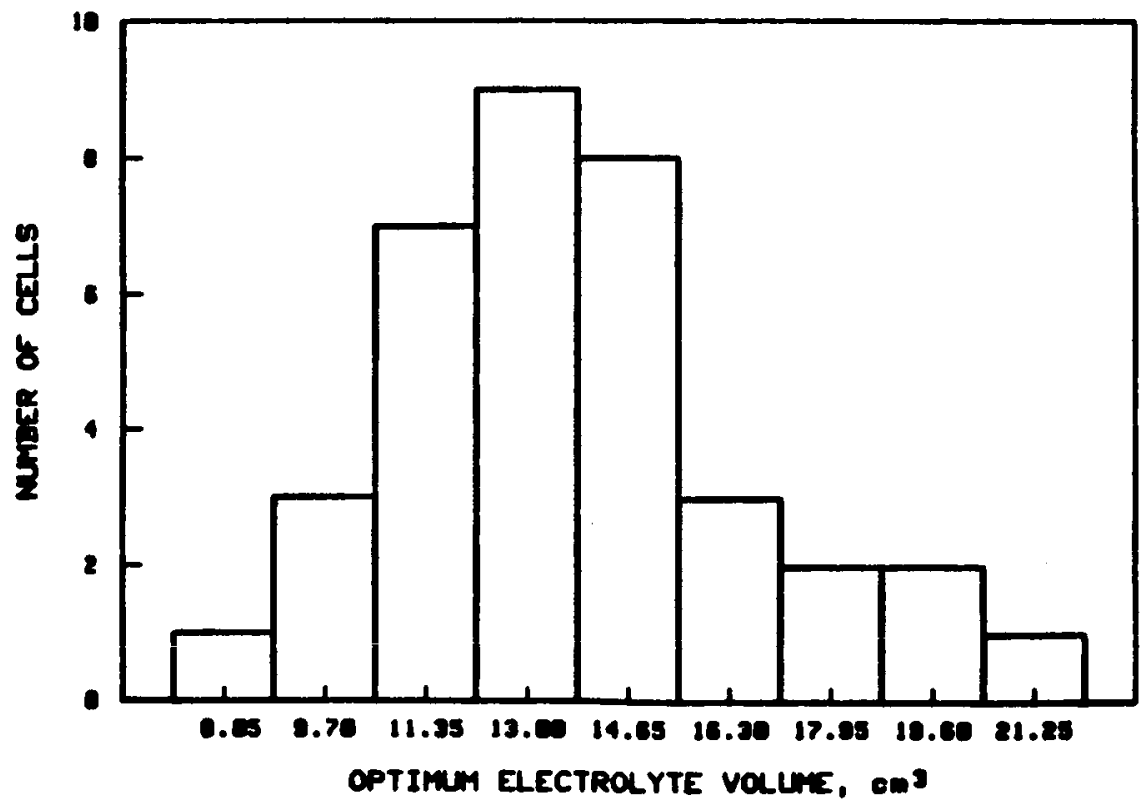

Figure 2. DISTRIBUTION OF OPTIMUM ELECTROLYTE VOLUMES 


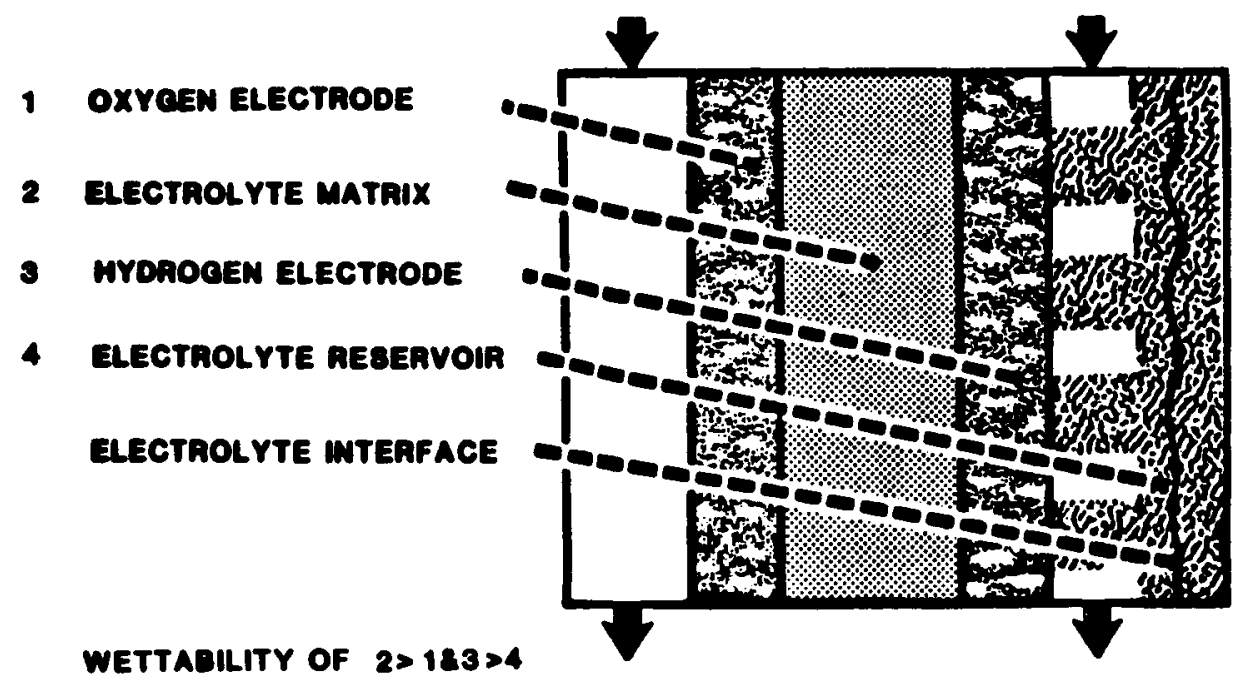

Figure 3. FUEL CELL EMPLOYING ELECTROLYTE RESERVOIR

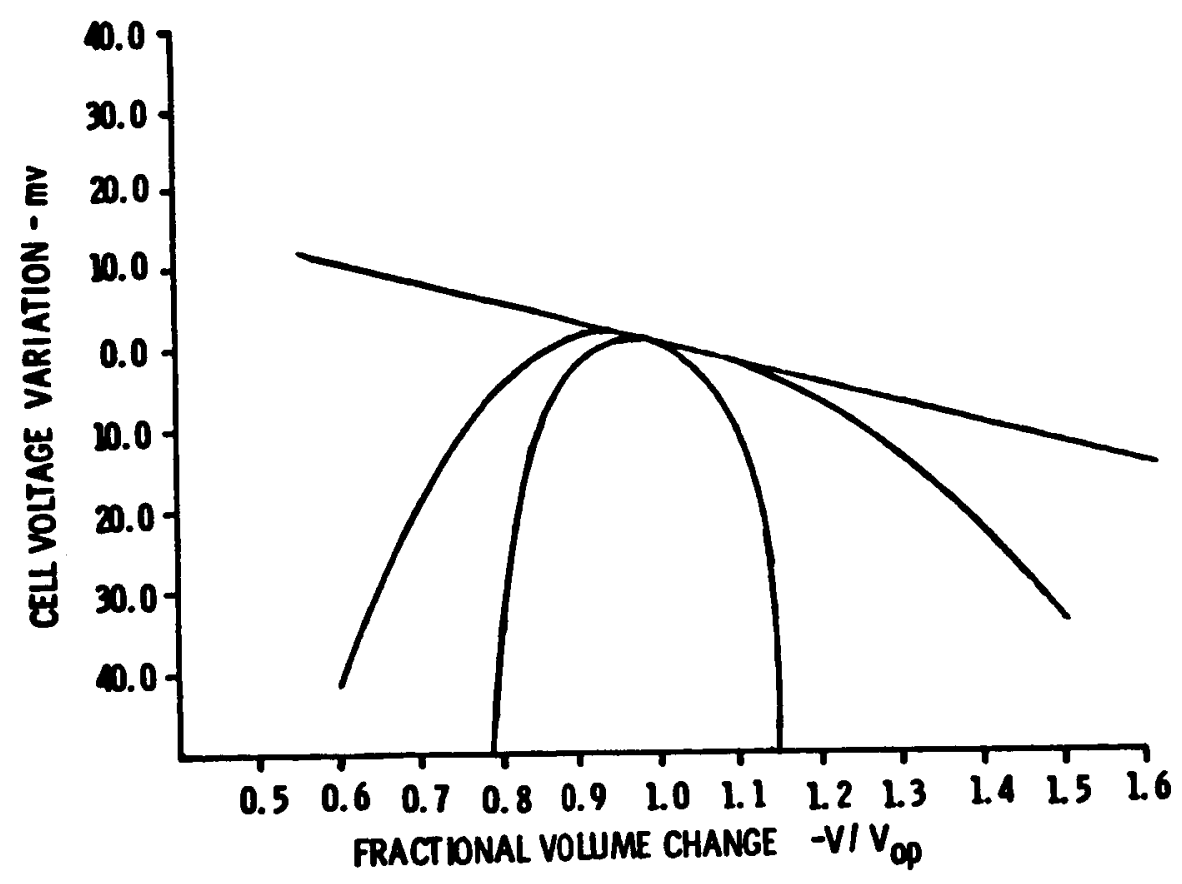

Figure 4. CELLS CAN BE CONSTRUCTED WITH DIFFERENT DEGREES OF VOLUME TOLERANCE 


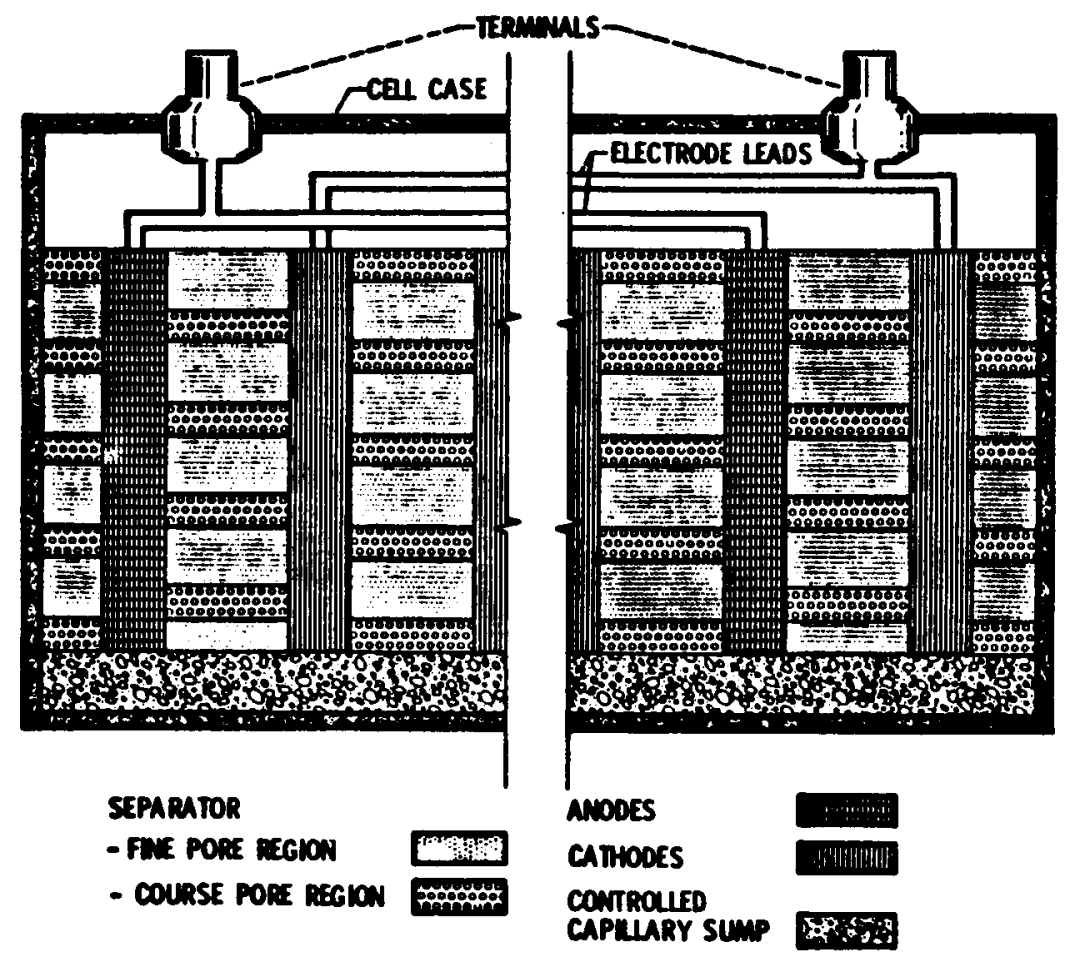

Figure 5. A FLOODED-STARVED DESIGN FOR NICKEL-CADMIUM CELLS 